\title{
4. Mapping Early Epidemiology: Concepts of Causality in Reports of the Third Plague Pandemic, 1894-1950
}

\author{
LUKAS ENGELMANN
}

The science of epidemiology has always had an intricate relationship to the history of diseases. The design of models of the dynamics that govern diseases in their relation to population is ultimately based on information and data gathered from past outbreaks. Epidemiology belongs to what Lorraine Daston has recently called "Sciences of the Archive."' Like astronomy, zoology, demography, or meteorology, the study of epidemics operates with objects of superhuman scale. The discipline deals with plagues that exceed historiographical periods and geographical regions; and, thus, it always requires elaborated practices of collecting, accounting, and archiving to establish its status as a discipline. Daston reminds us that despite this reliance of some "hard" sciences on the historical record, their conduct of history often differs from the perspective of humanists on the same historical event. Where exegesis, commentary, and interpretation of contexts and niches might characterize a history of diseases and epidemics, the epidemiological grasp on the historical record seeks to collect quantifiable data.

But epidemiology wasn't always a science of mathematical analysis, concerned with the production of formal expressions and the elaborate design of stochastic models. The epidemiology of the late nineteenth and early twentieth centuries is best described as a broad interdisciplinary project, suspended between isolated academics in medical schools and a growing group of governmental medical officers applying a mixture of methods, integrating 
historical, anthropological, sociological, statistical, and medical approaches to understand diseases in relation to populations and environments. $^{2}$

Nineteenth-century epidemic outbreaks of cholera, smallpox, or bubonic plague were not captured in statistical data alone, but were regularly packaged into narratives. These narratives were built around detailed observations to discuss and propose arguments about causes, the significance of local conditions, and the efficiency of mitigating practices. The genre of the outbreak report is often ignored in the historiography of epidemiology, which predominantly focuses on the development of statistical methods and mathematical models. However, the narrative form of capturing and classifying epidemic outbreaks was crucial to the broad interdisciplinary nature of epidemiological reasoning at the time. Historically, the genre of the outbreak report exhibited similarities to the clinical case report and its capacity to stitch detailed observations of singular cases to systematic considerations of the characteristics of the disease. ${ }^{3}$ Much in the same way, the outbreak report presented a singular outbreak to other epidemiologists to engage debates about common aspects of particular local conditions and to contribute to the production of generalizable characteristics of an epidemic.

The aim of this chapter is to rediscover the outbreak report as a long-overlooked source of fine-grained and systematic epidemiological observations. The texts contain a wide range of valuable information, reaching from individual case reports over dispersed mortality and morbidity statistics to sections about causation theories and observations of treatment and prevention practices. ${ }^{4}$ This information is currently not available as structured data and is dispersed throughout the texts in semi-structured formats. The first goal of this paper is therefore to evaluate pathways of extracting this information through text mining. I will present steps and considerations of a thorough analysis of the given structures of the outbreak report and will introduce formalization strategies to arrive at structured datasets, which could eventually 
be attached to metadata including the location and dates of outbreaks. While this data might be of interest to epidemiologists, this paper will also provide reflections from the perspective of the historian, who is keen to preserve the value of historical analysis in this process. The guiding concern in the following pages is to design systems for structuring the narrative information that preserve difference, local deviation, and conceptual incommensurability within and across the reports. The historical report is not a source that enables us to refine and consolidate accurate epidemiological concepts of bubonic plague; rather, it allows for the epistemological analysis of historical ways of seeing the epidemic. ${ }^{5}$

The second, but by no means secondary, goal of this study is then to draw out feasible methods of extracting the structure and composition of epidemiological argumentation, to understand how epidemics were seen and how they were reasoned about. The reports allow for a careful reconstruction of the interdisciplinary nature of reasoning in pre-formal epidemiology. Historical sections illuminate the use of the natural histories of diseases. Arguments about incidence among different populations enhance our understanding of the anthropological and colonial frameworks through which epidemics were conceived. Considerations about local conditions and speculations about causes provide a basis to reconstruct the ecological and environmental arguments that underpinned much of the understanding of infectious diseases at the time.

Network analysis supported by natural language analysis enables both epidemiological as well as epistemological interests in the history of diseases. Polemically speaking, the "what" of the history of an epidemic outbreak can be brought into a productive relationship with the "how" of its interpretation at the time and place of observation. Building a model for the extraction of data about clinical observations, climatic conditions, or causal relations will have to integrate the structure and form of how these aspects were presented and will lay bare the conventions of the genre of outbreak reports. Reflecting and discussing the conceptual aspects of the 
development of a pathway for successful data extraction will thus deliver insights into the structural underpinnings of the complex epidemiological reasoning from a time when epidemiological science was not predominantly perceived as a mathematical exercise.

The pilot study presented in this chapter focuses on a small sample of outbreak reports of one disease and one particular aspect of its epidemiology. I am particularly interested in reports that cover local outbreaks of the third plague pandemic from 1894 to 1950. The return of the disease from the Middle Ages ignited extensive epidemiological interest at the end of the nineteenth century. The disease's global distribution, its challenge to modern institutions of hygiene and sanitary cleanliness, as well as its unexplained dynamics on the heel of the successful identification of its infectious agent makes it an excellent case for the questions outlined above. ${ }^{6}$ The reports offer a broad sample of late nineteenth-century conventions of epidemiological reporting as they contain a vast amount of speculations about local influences, causal relations, disease vectors, and the epidemic's containment. Finally, the duration of the third plague pandemic over six decades also bridges a timespan of dramatic epistemological transformation in the field of epidemiology, as formal methods and mathematical models began to take center stage in the 1920 s. $^{7}$

Two kinds of networks can be envisioned in this sample. The first network would include the outbreaks of plague structured by arguments made about local conditions. Each report of plague presents a node, associated with an outbreak within the network of the pandemic spanning geographical and historical dimensions. It would be possible to map outbreaks where the authors suggest a strong importance of seasonal influence or to look at those outbreaks emphasizing racial arguments about the incidence of plague. Individual cases could be compared along the global sample and treatment as well as prevention methods could be contrasted with traditional maps of plague incidence. Second, it appears to be possible to trace networks of arguments made within each outbreak 
report to better characterize the epidemiological reasoning about plague in Hong Kong or Sydney and to contrast it with other cities around the world. Instruments from epistemic network analysis could be used to visualize the argumentative structures of outbreak reports as well as to visualize the observations and details associated with causality, contrasting them with the argumentative elements essential to historical narratives about plague. ${ }^{8}$ However, these visualizations have not yet been made but, rather, stand as the goal of the project, once the structuring has been concluded.

In this chapter I describe some of the early steps necessary to achieve these network visualizations. Then I explain in detail the thought processes I applied to transform a narrative genre into a structured dataset. I focus particularly on one theme that runs through all the reports, across outbreaks in multiple places and periods: namely, the question of cause. Especially in the case of plague, questions of causality exceeded bacteriological findings in the laboratory. Despite the successful identification of Yersinia pestis as the infectious agent of plague in 1894, subsequent epidemiological investigation looked at configurations, vectors, and the environmental conditions that could have led the bacteria to cause infections and outbreaks. In other words, one of the most important concerns for epidemiologists working on plague outbreaks was to understand the specific local condition that had caused an unusual amount of cases of plague clustered within a confined space and developed over a short period of time. Network analysis will eventually enable a visualization of the considerations of causes with the expectation to demonstrate clearly the stark variety of identified causes between places and a shifting conceptual focus on causality over time. The first step, however, is to identify sections in the reports that are relevant to the discussion of cause. Then we need to introduce meaningful separations between different concepts of causality. First, though, we need some background. 


\section{Early Epidemiology}

Modern epidemiology is conventionally considered to have begun in the nineteenth century. With the emergence of modern scientific methods, in addition to the rising significance of population as a calculable entity since the eighteenth century, epidemics became a new object of knowledge. The question that manifested itself quite distinctively in the second half of the nineteenth century was to what extent epidemics could be understood in their own right, differing from singular cases not only in quantitative but also in qualitative terms. ${ }^{9}$ How could knowing about populations and their dynamics be exploited to better understand the conditions and laws that seem to govern epidemics? Across Europe, its colonies, and the US, a growing community of physicians, public health officials, and medical officers began to investigate repeating patterns of epidemic outbreaks of cholera, smallpox, tuberculosis, syphilis, or plague.

The epidemiologist Alfredo Morabia has suggested framing the epidemiological practice of the nineteenth century as "pre-formal epidemiology."10 As an epidemiology void of theory and conceptual underpinning, it lacked the foundations to address its most pressing problems in a formal and systematic way. While this claim surely helped to distinguish the introduction of mathematical methods in the early twentieth-century history of the field, it is the aim of this paper to challenge such diagnostics of the nineteenth-century epistemology of epidemiology. Rather, I suggest to look at early epidemiology as a field that is defined by three distinctive, often loosely defined, but nevertheless constitutive frameworks of analysis. With Andrew Mendelsohn, we can differentiate these into statistical, environmental, and historical approaches. ${ }^{11}$ While these three approaches might have lacked an overarching theoretical systematization, each of these frameworks were theorized and conceptualized in their own right. ${ }^{12}$

Perhaps the most visible (and, at least since the mid-nineteenth century, the most important) instrument in epidemiology was statistics. Famously attached to the work of William Farr and John 
Snow, statistical analysis of cholera outbreaks had changed the ways in which arguments about epidemics were made. Statistics provided a reliable method of measuring and evaluating the impact of disease on society, while encouraging new ways of questioning society's own involvement in the cause, spread, and exaggeration of diseases. ${ }^{13}$ Population was not anymore seen to be an amorphous entity, but could be separated in different populations along a broad line of concepts reaching from habitation, to nutrition, to factors like age and heritage. ${ }^{14}$ With attempts to separate populations into affected/non-affected or exposed/non-exposed parts, both Farr and Snow took inspiration from the mathematical work of Laplace, Poisson, and Bernouli. But late nineteenth-century epidemiologists were also influenced by a number of emerging sciences in which the compartmentalization and calculation of populations took on further significance. Quetelet's early approaches to statistical mean values of physiological aspects (such as height, the introduction of evolutionary biology, or the production of economic theory) might have contributed to the attraction of statistical thinking in epidemiology. All of these approaches showed that when looking at complex human events in aggregate forms, even those intentionally and willfully created, they seem to exhibit law-abiding tendencies. ${ }^{15}$

Beyond the calculation of population, the environment was an important object of epidemiological consideration. To many early epidemiologists, the environment provided an ideal vehicle to conceptualize ambitious sanitary reforms merging political and medical motives. Many early epidemiologists continued the traditional skepticism of William Farr about contagion and principles of infection to advance epidemiology as a sanitary science. ${ }^{16}$ The environment served as placeholder for a multitude of factors, which influenced the cause, distribution, and exaggeration of diseases. As Anne Hardy has emphasized, this led to the development of a "highly environmentalist, observational tradition" in the conduct of epidemiological analysis. ${ }^{17}$ Factors like stench and noxious vapors were considered as much as bad air or emanating influences from the soil. ${ }^{18}$ Charged with various theories and 
conceptual underpinnings, the environment remained a constant epidemiological concern throughout the nineteenth century and even in the face of reductionist bacteriological aetiologies, providing an open-ended repository for the conceptualization of causation.

Third, traditional epidemiology was indebted to a historical method. Epitomized in the geographical-historical work of August Hirsch, historical narratives of the origin and distribution of epidemics were regularly considered to be of eminent analytical value in the interpretation of occurring epidemics. ${ }^{19}$ The history of epidemics, often including their ancient origins, was more than just illustrative contextualization. ${ }^{20}$ Instead, the historical narrative was seen as a conceptual element through which epidemics achieved their status of transhistorical entities, and understanding their history enabled diagnosis as much as prognosis. Amassing the historical events of an epidemic, so believed historical geographers like Hirsch, allowed for productive generalizations. Similar to the production of clinical records, it was the identification of series and seriality throughout an epidemic's history that contributed to its understanding in the present. ${ }^{21}$

Without diminishing the significance of statistical methods, it is important to acknowledge that epidemiology of the nineteenth century was fundamentally driven by text-based methods. Assessments of environment relied on refined practices of observation and their empirical, sober reporting, while the building of the historical background of an epidemic was fundamentally an art of storytelling. Although historical geography of disease included the production and invention of new forms of mapmaking, key reference works such as Hirsch's vademecum were exclusively text-based works. The outbreak reports of plague should therefore be considered to offer much more than mortality rates, case numbers, or dates relevant to the outbreak. The reports also provide both interested historians as well as epidemiologists with rich descriptions, detailed discussions, and decisive arguments about 
the local environment and its multifaceted relation to the disease. Moreover, each of the reports offers its own version of the long history of bubonic plague.

\section{The Case of the Third Plague Pandemic}

This study focuses on the third plague pandemic for various reasons. Usually accredited to an outbreak in 1894 Hong Kong, the third global occurrence of plague was distributed along the trade routes of growing sea commerce and affected almost every port city in the world in the following decades. ${ }^{22}$ But outbreaks differed in severity, mortality, and longevity, and prompted a wide range of different measures mounted to halt the epidemic's distribution. Within the first year of the new outbreak of bubonic plague, its bacteriological agent was identified, first by Shibasuro Kitasato and later by Alexandre Yersin. ${ }^{23}$ The emerging global crisis, with catastrophic effects especially in colonial India, could not be quickly resolved despite the successful identification of the bacteria. It was rather the sanitarians and their epidemiological expertise, which became of high value to identify and to explain the mechanism through which plague was distributed. ${ }^{24}$ Plague became a showcase for early epidemiology to demonstrate that it was the exclusive scientific practice that could explain the prevalence for plague to devastate some port cities while leaving others unharmed.

To epidemiologists in the late nineteenth century, plague must have appeared as a paradigmatic set of questions. With the problem of etiology out of the way and relegated to the laboratory, epidemiologists could demonstrate the capacities of their knowledge practices to explain an epidemic event. ${ }^{25}$ Because this plague was a global disease-a pandemic-it also gave ample opportunity to engage with any of the large frameworks of epidemiological reasoning that persisted at the time, including population, environment, and history. 
Statistical work was employed to understand precisely how plague's relationship to population differed from the disease appearance in an individual case. ${ }^{26}$ The high mortality rate and the quick progression of the disease in individual cases led to the appearance of a slow onset of the epidemic as an aggregate of cases. Moreover, plague was often perceived through racial and ethnic filters, which in turn prompted extensive comparison of populations. $^{27}$

Nevertheless, one of the most fundamental concerns of the plague epidemiologists was the relationship of the disease to its physical environment. This invariably included further concerns about infection pathways and of conditions of the soil or food, which might provide opportunities for bacteria to survive outside of the human host. ${ }^{28}$ What kind of surroundings did encourage or diminish the course of the epidemic? Under which conditions did the bacteria thrive, and what contributed to its containment? What emerged was not only a re-fashioning of the old sanitarian's obsessions with cleanliness and hygienic appearances, but a new focus on conditions under which a bacteria's capacity to infect and to lead to the outbreak of a case of plague was increased or attenuated. This subject, often referred to at the time as virulence, marked precisely the difference between the observed behavior of a bacteria in the laboratory and the invisible conditions of it leading to a disease on the epidemic streets. ${ }^{29}$

Plague was also widely seen as the return of a historic disease, a disease of the Middle Ages that had been overcome by Western civilization. This history was used as a repository for symptombased diagnostics, comparing old descriptions to the occurrences in the nineteenth century. But references also were drawn regularly to the epidemic's younger history, comparing outbreak reports from Egypt and Russia with the series of events that characterized the third plague pandemic.

Finally, with the arrival of the third plague pandemic, the transnational dimension of epidemiology would prove to be crucial. Plague was perhaps one of the first epidemics registered by its 
contemporaries as a global event. Epidemiologists had to develop a system of accurate comparison that sought to understand the difference in places with regards to all of the factors above. Different populations with varying demographics were subjected to changing climatic conditions, followed different cultural customs, were considered to belong to different racial, ethnic or cultural groups, and had developed different ways of responding to the

plague. Outbreaks in cities around the world needed to be compared and discussed along the lines of their statistical significance and the specifics of their environmental conditions to understand how they form an event within the series of outbreaks that formed the pandemic on a global scale. For this purpose, epidemiologists, sanitary officers, local physicians, and national health officers produced accounts of local outbreaks, written up and drawn together in outbreak reports which were then disseminated globally.

\section{The Bubonic Plague Report}

Almost every significant outbreak and many minor incidents of plague have been reported in a more or less formalized way since the first outbreak of the third plague pandemic in Hong Kong in 1894. My non-exhaustive list of reports consists currently of about 50 unique entries. For pragmatic reasons, the list is limited to English-language reports. ${ }^{30}$ For the purpose of this study, I excluded reports that provided only a general account of the disease as well as those that focused on a single case. All of the reports in the list discuss the specific occurrence of multiple plague cases clustered around a location and occurring within a limited timeframe. While the geographical scope of a report is usually urban, I have also included reports considering nations or regions.

Methodologically, I have considered linguistic approaches to the definition of the epidemiological outbreak report as a genre of communication. The report could then, however anachronistically, 
be considered consistent with English for Specific Purposes (ESP). ${ }^{31}$ Here, as discussed by Bathia, a definition would apply in which the outbreak report is seen as a "communicative event with a particular purpose which is readily identified by what they refer to as its discourse community (those people who regularly engage in it). ${ }^{32}$ The report achieves its purpose through the realization of a sequence of what Swales and Bhatia have called moves and component steps. While the sequence may vary-moves and steps might occur in different orders and different realization patterns-each sequence component can, in theory, be isolated and analyzed as a schematic structure. Looking at the epidemic outbreak report, the following questions are essential:

A) What is its communicative purpose?

B) How were these purposes achieved through the schematic structuring of its moves and steps?

C) To what extent can a systematic schematic structure be generalized across the genre?

I assume here that the epidemic outbreak report serves the overarching communicative purpose of describing and explaining the relationship between the disease and the location for which the report is written. This relationship is complex, and its variation from case to case and from report to report is of key interest to this pilot study. My hypothesis is that all reports-despite the multitude of possibilities in which local conditions are described and related to the variable understandings of bubonic plague-follow a fairly conventional way of presenting and structuring their arguments, as they utilize the same moves and steps. After all, the corpus of reports can be considered a genre because each report tends to follow conventions of reporting that address concerns of the intended audience, usually government officials or fellow epidemiologists.

A first step to zone the documents along the scheme that undergirds the reporting is based on the structures that report authors have applied through headings and sections. Additional to the standard inventory-a preface, an introduction, and occasionally a conclusion-all other sections of the reports appear to repeat 
a scheme characteristic for reporting on plague outbreaks across places and time. After the aggregation of all sections from all reports in this sample, 11 categories have been devised to cluster the majority of existing sections. This scheme preserves the moves and steps of the outbreak reports, and although it doesn't necessarily reflect their original order, it enables comparison of these steps across the reports and thus across outbreaks.

Table 4.1: Sequence titles that represent the scheme of reporting on epidemic events identified across the outbreak reports in the given sample

\begin{tabular}{lll}
\hline \# & Sequence title & Description of Content \\
\hline 1 & $\begin{array}{l}\text { Title matter, } \\
\text { preface }\end{array}$ & Title page and letters in the preface \\
\hline
\end{tabular}

State of the epidemic at the time of the production of the

2 Introduction report, summary of key features, evaluation of significance of the epidemic, history of disease, history of outbreak, short overviews of the epidemic's course

\begin{tabular}{lll}
\hline 3 & $\begin{array}{l}\text { History of } \\
\text { Disease }\end{array}$ & $\begin{array}{l}\text { General points on the history of the epidemic, origin of } \\
\text { outbreak }\end{array}$ \\
\hline 4 & $\begin{array}{l}\text { History of } \\
\text { Outbreak }\end{array}$ & Geographical and chronological overview of local outbreak \\
\hline 5 & $\begin{array}{l}\text { Local } \\
\text { Conditions }\end{array}$ & $\begin{array}{l}\text { Descriptions of key elements that are considered noteworthy } \\
\text { by the author in relation to plague }\end{array}$ \\
\hline 6 & Causes & $\begin{array}{l}\text { Causes identified by the author. Usually points of origin, } \\
\text { specific local conditions or descriptions of import, later } \\
\text { zoonotic factors }\end{array}$ \\
\hline
\end{tabular}
List of the measures undertaken to curb the outbreak,

7 Measures sanitary improvements, quarantines, disinfection or fumigation and rat-catching, poisoning, education, behavioral changes, treatment given as prophylaxis

\begin{tabular}{cll}
\hline 8 & $\begin{array}{l}\text { Clinical } \\
\text { Appearance }\end{array}$ & $\begin{array}{l}\text { Description of the diseases appearance, its usual course and } \\
\text { its mortality }\end{array}$ \\
\hline 9 & Laboratory & Description of bacteriological analysis, other laboratory work \\
\hline 10 & Treatment & Description of the treatment given to patients \\
\hline 11 & Cases & $\begin{array}{l}\text { List of individual cases, usually with age, gender, occupation, } \\
\text { course of disease, and time and dates of infection and death }\end{array}$ \\
\hline
\end{tabular}

Table 4.1 indicates the sequence titles that I have chosen to apply on the aggregated section titles from the outbreak reports. I added a short description of the expected content of the sequences. Some reports have additional sections, which are concerned with details 
beyond this scheme; these will be registered for the time being as "other." Additionally, many of the shorter reports do not have sections, so I have broken up the text where possible into the appropriate categories.

\section{Visualizing Causation: Three Examples from Bubonic Plague}

My goal here is to a) consider arguments made in the reports about the causes of bubonic plague in specific outbreak locations, and b) showcase a possible way to structure those arguments. To this end I have identified the sections across the sample that can be identified with the sequence title "Causes" and have transferred them into a discrete dataset for further analysis. After experimenting with various tools and instruments I found simple word counts to be surprisingly accurate to match the arguments presented by the reports. To this end I counted the frequency of significant terms in the sections identified and classified as "Causes." Afterwards, a classification of significant words among the ten most frequent terms provided for a vague, but accurate, identification of argumentative classes. These classes could be translated to match themes or motifs that were considered by the authors of the report when looking into the local causes for an outbreak. I will present here three examples to demonstrate the method.

The first example is taken from a report on Hong Kong's 1894 plague outbreak, the first outbreak in the history of the third plague pandemic. The author of the report is the colonial medical officer James Lowson, and in it Lowson includes a section titled "Causes" in which he discusses his observations and hypothetical considerations of what caused plague to appear suddenly and devastatingly in the district of Taipingshan in Hong Kong. ${ }^{33}$ After removing stop-words and standardizing multiple forms, the 
resulting list gives a clear picture of Lowson's thinking on what caused plague. I applied a preliminary classification of the terms to quickly visualize the characteristics of causation this report implies.

Table 4.2: Standardized word count for "causation" sequence in outbreak report for 1894 Hong Kong

\begin{tabular}{lll}
\hline Count & Term & Class \\
\hline 23 & Latrine & Built Environment \\
14 & House & Built Environment \\
10 & Street & Built Environment \\
8 & Case & Condition \\
7 & Epidemic & Condition \\
6 & Disease & Condition \\
5 & Chinese & Population \\
5 & Overcrowding & Population \\
5 & Well & Built Environment \\
5 & Hong Kong & Location \\
\hline
\end{tabular}

This simple analysis shows that Lowson is focused on the material configurations of the urban environment. "Latrine," "house," and "street" appear as the pivotal points of concern, here classified as aspects of the "built environment." By associating the terms "case," "epidemic," and "disease" with the class "condition" Lowson leads one to expect that at least a number of sentences in this sequence will include strong connections-or at least significant proximity-between terms indicating "condition" and those associated with "built environment." The following two terms ("Chinese" and "overcrowding") further indicate that the built environment is accompanied by the allocation of causes to Chinese aspects, here coded as a qualification of the class "population." This weighted word list demonstrates the sanitary perspective of Lowson, and the order visualized in the table resembles his argument that plague was driven by what he conceived of as an unsanitary state of Chinese life, manifested in the built environment. 
The second example is a report written by Ernest Hill from the London School of Hygiene and Tropical Medicine concerning the outbreak of plague in the South African city of Natal in $1902 .{ }^{34}$ Two sequences zoned as "Cause" are titled "Relation to Race, Sex, Age, Occupation, and Surroundings of Dwellings" and "The Manner in which the Disease spread." As the title of the first section indicates, Hill did not primarily focus on the urban environment, but rather attributed the causes for the distribution of plague to the question of population.

Table 4.3: Standardized word count for "Cause" sequence in outbreak report for 1902 Natal

\begin{tabular}{lll}
\hline Count & Term & Class \\
\hline 52 & Case & Condition \\
17 & Infected & Condition \\
15 & Plague & Condition \\
14 & Person & Population \\
12 & Tenement & Built Environment \\
11 & Man & Population \\
10 & Durban & Location \\
9 & Disease & Condition \\
7 & Indians & Population \\
6 & Place & Built Environment \\
\hline
\end{tabular}

The table shows that terms associated with "condition" rank highest in this chapter. While it is difficult to ascertain why this is so, it might prove interesting to look into the significance of "cases" for the arguments made in this sequence. The association of "infected" and "person" indicates that Hill, in contrast to Lowson in Hong Kong, argued about causation mostly in connection to infected population and perhaps their behavior or their identity. While the "built environment" is not excluded from his considerations, it ranks comparably low, and the usage frequency of both "tenement" and "place" suggests a secondary significance. This ranks on the same 
level as the "Indians" designation under "population," which seem to have some, but not much importance to the elaboration of causes for plague in this case.

In this example, decisive limits to this method become quite clear. These limits might be mitigated by integrating further analysis of collocation of terms to identify units of meaning beyond singular terms. However, Hill does indeed state in the text that there seem to have been no indications for a disproportionate distribution of plague cases among people he describes as "Indians." A preliminary conclusion could therefore be that the vagueness of the results listed above is indeed indicative of the vagueness present in Hills writing about causes.

The third and final example is taken from a report about an outbreak of plague in Peru in 1932. The report is written by the American epidemiologist Charles Eskey. ${ }^{35}$ Sequences that have been zoned as "Cause" were called "Relation of rat species to plague," "Relation of flea species to plague," and the "Summary" for both of these sections. In this report, published a good three decades later than the other two, a very different picture of epidemiological reasoning about causes for plague has been established.

Table 4.4: Standardized word count for "Cause" sequence in outbreak report for 1932 Peru

\begin{tabular}{lll}
\hline Count & Term & Class \\
\hline 62 & Rat & Animal \\
41 & Plague & Condition \\
23 & Cheopis & Animal \\
23 & Building & Built Environment \\
20 & Caught & Measures \\
15 & Peru & Location \\
12 & Place & Location \\
12 & Index & Laboratory \\
11 & Human & Population \\
10 & Communities & Population \\
\hline
\end{tabular}


The word count in Table 4.4 shows a very different picture of the consideration of causes for plague. Both the highest and the third most frequent term are now concerned with animals-"rat" and the rat flea "cheopis"-which were by that time accepted as principal vectors of bubonic plague. The concern over built environment has certainly not disappeared, but in this context it appears as the environment of the principal vector rather than a concern of infection in and by itself. Furthermore, the presence of location as well as population at the end of the list is interesting; it appears almost as if the hierarchy of terms resembles the causal chain identified in the field. The word list delivers a fairly accurate picture of Eskey's perspective, as he believed that plague was indeed driven by rats and fleas and that the considerations of the built environment and geographical aspects had to be undertaken in relation to the zoonotic factors that undergird the propagation of bubonic plague before it affects humans and communities.

These three examples are preliminary. I've included them here to show how one might go about building a structured dataset out of a fairly unstructured list of documents. With the above examples, I've shown that simple word counting, within a carefully zoned sequence of text, yields results that largely match the arguments made by the authors. The word lists deliver obvious hierarchies, which indeed catch the themes and concepts of causation used in various places and times, once they have been classified in a sensible and historically sensitive way. My hope is that by expanding this method to other examples and by integrating the term collocation I will end up with a robust set of classifications useful for network visualizations.

\section{Discussion and Outlook}

This method of visualizing the conceptual underpinnings of causality in plague outbreaks is clearly far from satisfying my goal of representing the specific arguments made in each of these reports. 
The word lists are useful insofar as they foreground categories and concepts that were indeed significant to the attribution of causes in 1894 Hong Kong, 1902 Natal, and 1932 Peru. The shift from broad considerations of the urban environment to a focus on population to the identification of rats and fleas as principal vectors is well aligned with the arguments presented in the reports (as well as with the historical scholarship) about these outbreaks and their perception at the time.

The method discussed in this paper offers an overview of how causation of bubonic plague was perceived differently in three places. To the historian interested in the epistemology of epidemiology, these abbreviations of the sections might be useful for the construction of concepts assumed to be influential in the production of epidemiological knowledge. Clearly, with the current size of the sample, simply reading the reports will offer deeper insights and more reliable conclusions. But the purpose of the experimental zoning and structuring of the report as discussed above, was not to replace the traditional approach to these historical sources but to outline a method of modeling epidemiological reasoning.

Moving forward, my aim is to refine this method and to train a model that reliably resembles the arguments in reports. This will enable large-scale comparison across all outbreak reports and sections to deliver two modes of network visualization. First, this method allows for a visualization of networks of concepts and theories that structured the epidemiological observation of plague. To historians working on the history of the third plague pandemic, this will be a useful instrument to trace theories and practices along the network of outbreaks. It will be possible to trace networks of expertise through the references included in reports as well as to create an inventory of person names involved in the research on plague on a global scale. Patterns of fumigation practices might follow the political contours of an empire, and patterns of treatment protocols might be indicative for the global reach of the Institut Pasteur. Furthermore, practices of prevention can be compared to 
concepts of causation to identify, for example, inconsistencies. Moreover, a plethora of data would be made available for epidemiological analysis, including mortality and incidence rates, dates and individual case descriptions accompanied by detailed datasets to enrich models of the dynamics of bubonic plague.

Second, network visualizations of each report can be created to demonstrate the weight of arguments and concepts in individual texts. Utilizing epistemic network analysis, these networks of epidemiological reasoning will be useful to enhance our understanding of the formal underpinnings of pre-formal epidemiology. The sample of bubonic plague reports, spanning the decades from 1894 to 1950, contains important shifts in the significance of the animal vector, for the role of the laboratory, and for the rising position of mathematical models. The reports offer a rich sample to better understand the role of the environment and its significance for epidemiological arguments. Historical narratives of the plague can be compared over time to gain insight into the role of history for epidemiological analysis.

Once these research practices have been developed and tested, the model can be used far beyond the genre of outbreak reports. It might very well provide us with an instrument to crawl through large collections of digitized works in the history of medicine and public health to retrieve meaningful new information about the history of the third plague pandemic. Important questions about concepts of causes, about the dates and places of specific measures and about the emergence of theories about the vector of the rat could be raised against the entirety of sources available through the Medical Heritage Library. Such efforts promise new research questions and will enrich our understanding of the historical contingency of observing and understanding epidemics. 


\section{Appendix: A List of Outbreaks}

Ayres, Philip Burnard Chenery, and James Alfred Lawson. Report on the Outbreak of Bubonic Plague in Hongkong, 1894, to the International Congress of Hygiene and Demography Held at Budapest, 1894. Hong Kong: China Mail Office, 1894. http://archive.org/details/b24974407.

Baxter-Tyrie, C. C. "Report of an Outbreak of Plague in Queensland during the First Six Months of 1904." Journal of Hygiene 5, no. 3 (1905): 311-32.

Blackburne, G. H. S., and T. L. Anderson. Report on the Outbreak of Plague at Fremantle. Perth: Wm. Alfred Watson, Government Printer, 1903. http://archive.org/details/b24916614.

Bombay. Municipal Commissioner's Office. Report of the Municipal Commissioner on the Plague in Bombay for the Year Ending 31st May 1901. Bombay: Advocate of India Press, 1902. http://archive.org/details/b28037510 0003.

Bombay Plague Committee, James M. Campbell, and R. Mostyn. Report of the Bombay Plague Committee, Appointed by Government Resolution No. 1204/720P, on the Plague in Bombay, for the Period Extending from the 1st July 1897 to the 30th April 1898. Bombay: Times of India Steam Press, 1898. http://archive.org/details/ b24974535.

"Bubonic Plague." Journal of the American Medical Association XXXIII, no. 22 (November 25, 1899): 1366-1366. https://doi.org/ 10.1001/jama.1899.02450740054010.

"Bubonic Plague in Bombay." Journal of the American Medical Association XXXI, no. 1 (July 2, 1898): 29-30. https://doi.org/ 10.1001/jama.1898.02450010039005.

"Bubonic Plague in San Francisco." Journal of the American Medical Association XXXV, no. 19 (November 10, 1900): 1213-14. https://doi.org/10.1001/jama.1900.24620450029001j.

California, and California State Board of Health. Report of the Special Health Commissioners Appointed by the Governor to Confer with 
the Federal Authorities at Washington Respecting the Alleged Existence of Bubonic Plague in California: Also Report of State Board of Health. Sacramento: A.J. Johnston, Supt. State Print, 1901.

Calmette, Albert. "The Plague at Oporto." The North American Review 171, No. 524 (Jul., 1900), 104-11.

Fabela, O. G. "Something about the Bacteriology and Clinical History of Plague." Public Health Papers and Reports 29 (1903): 255-58.

Gatacre, William Forbes (Sir), and Bombay Plague Committee. Report on the Bubonic Plague in Bombay, 1896-97. Bombay: Times of India Steam Press, 1897. http://archive.org/details/ b24974523 0003.

Goff, A. P. "Bubonic Plague in Manila." Journal of the American Medical Association 60, no. 26 (June 28, 1913): 2042-43. https://doi.org/10.1001/jama.1913.04340260016009.

Great Britain. Local Government Board, and Royal College of Physicians of London. Reports and Papers on Suspected Cases of Human Plague in East Suffolk and on an Epizootic of Plague in Rodents. London: HMSO, 1911. http://archive.org/details/ b24976775.

Grubbs, S. B. "The Plague Outbreak in Porto Rico." Journal of the American Medical Association LXII, no. 4 (January 24, 1914): 288-89. https://doi.org/10.1001/jama.1914.02560290038013.

Ham, Bertie Burnett, and Queensland. Department of Public Health. Report on Plague in Queensland, 1900-1907 (26th February 1900 to 30th June 1907). Brisbane: Department of Public Health, Queensland, 1907. http://archive.org/details/b28039099.

Ham, Bertie Burnett, and Queensland. Department of Public Health. Report on the Outbreak of Plague in Maryborough, 1905 [Electronic Resource]: May-June 1905. Brisbane: By authority: George Arthur Vaughan, Government printer, 1905. http://archive.org/details/ b21351582.

Ham, Bertie Burnett, and Queensland. Department of Public Health. Report on the Outbreak of Plague in the State of Queensland, 1903. Brisbane: George Arthur Vaughan, Government Printer, 1903. http://archive.org/details/b24916602. 
Havelburg, W. "BRAZIL. Reports from Rio de Janeiro-Plague Imported from Oporto. April 28, 1900" Public Health Reports 15, no. 23 (1896-1970): 1442-44.

Hill, Ernest Edward. Report on the Plague in Natal, 1902-3 [Electronic Resource]. London, Cassell, 1904. http://archive.org/details/ b2135392x.

James, C. H., Punjab, and Royal College of Physicians of London. Report on the Outbreak of Plague in the Jullundur and Hoshiarpur Districts of the Punjab, 1897-98. Lahore: Printed at the Civil \& Military Gazette Press, 1898. http://archive.org/details/ b24975886.

Liceaga, Eduardo. "The Bubonic Plague in the Port of Mazatlan, State of Sinaloa, Republic of Mexico." Public Health Papers and Reports 30 (1905): 226-37.

Lowson, James A. "The Epidemic of Bubonic Plague in Hongkong, 1894." The Indian Medical Gazette 32.6 (1897): 207-09.

Lowson, James A., Bombay, and Royal College of Physicians of London. Report on the Epidemic of Plague from 22nd February to 16th July, 1897. Bombay: Publisher not identified, 1897. http://archive.org/details/b24974511.

Lowson, James A., and Hong Kong. Colonial Secretariat. The Epidemic of Bubonic Plague in 1894. Medical Report. Hong Kong: Noronha \& Company, 1895. http://archive.org/details/ b24398287.

Mitra, A., and London School of Hygiene and Tropical Medicine. A Report on the Outbreak of Plague in Kashmir from 19th November 1903 to 31st July 1904. Kashmir: Central Jail Press, 1904. http://archive.org/details/b2476467x.

Montgomery, Douglass W. "The Plague in San Francisco." Journal of the American Medical Association XXXV, no. 2 (July 14, 1900): 86-89. https://doi.org/10.1001/jama.1900.24620280022001f.

Mullowney J. J. "The Plague in North China." Journal of the American Medical Association LVI, no. 10 (March 11, 1911): 737-737. https://doi.org/10.1001/jama.1911.02560100029011. 
Nathan, Robert. The Plague in India, 1896, 1897. Simla: Government Central Printing Office, 1898. http://archive.org/details/ plagueinindia18901nath.

Nathan, Robert. India. Home Department, and Royal College of Physicians of London. The Plague in India, 1896, 1897. Simla: Government Central Printing Office, 1898. http://archive.org/ details/b2497528x 0001.

New South Wales. Department of Public Health and Thompson, J. Ashburton. Report on the Outbreak of Plague at Sydney, 1900. Sydney: William Applegate Gullick, Government Printer, 1900. http://archive.org/details/b21354704.

New South Wales. Department of Public Health and Thompson, J. Ashburton. Report of the Board of Health on a second outbreak of plague at Sydney, 1902. Sydney: Government Printer, 1903.

Philip, W. M., and L. F. Hirst. "A Report on the Outbreak of the Plague in Colombo. 1914-1916." The Journal of Hygiene 15.4 (1917): 527-64.

"The Plague at Sydney." Journal of the American Medical Association XXXVI, no. 22 (June 1, 1901): 1565-66. https://doi.org/10.1001/ jama.1901.02470220039012.

"A Plague Focus in California." Journal of the American Medical Association LIII, no. 25 (December 18, 1909): 2106. https://doi.org/ 10.1001/jama.1909.02550250060009.

"Plague in California and the Anti-Plague Campaign." Journal of the American Medical Association LI, no. 12 (September 19, 1908): 1010-14. https://doi.org/10.1001/jama.1908.25410120054004.

"The Plague in China." Journal of the American Medical Association XXII, no. 25 (June 23, 1894): 960-960. https://doi.org/10.1001/ jama.1894.02421040028006.

"Plague in South Africa - Report of Brookline, Mass., Board of Health - 'American Medicine': A New Medical Journal - A So-Called Victory for Christian Science - Medical Notes." The Boston Medical and Surgical Journal 144, no. 15 (1901): 360-65. https://doi.org/10.1056/NEJM190104111441512. 
"A Report on the Last Epidemic of Plague at Hong Kong - Medical Notes." The Boston Medical and Surgical Journal 136, no. 22 (1897): 550-52. https://doi.org/10.1056/NEJM189706030002211.

"The Reported Appearance of Plague in Bombay." British Medical Journal, no. 2 (1896): 966.

"Reported Case of Plague in Ann Arbor, Mich." Journal of the American Medical Association XXXVI, no. 15 (April 13, 1901): 1049. https://doi.org/10.1001/jama.1901.02470150045010.

Roys, Charles K. "Report on the Epidemic of Pneumonic Plague in Tsinanfu 1918." China Medical Journal 32, no. 4 (1918): 346-48.

Simpson, W. J. (William John), and Great Britain. Colonial Office. Report on the Causes and Continuance of Plague in Hongkong and Suggestions as to Remedial Measures [Electronic Resource]. London: Waterlow and Sons, Printers, 1903. http://archive.org/ details/b21297496.

Simpson, William John, and Hong Kong. Sanitary Board. Preliminary Memoranda on Plague Prevention in Hongkong. Hong Kong: Noronha \& Co, 1902. http://archive.org/details/b24975242.

Simpson, William John. Report by Professor W. J. Simpson on Sanitary Matters in Various West African Colonies and the Outbreak of Plague in the Gold Coast. London: Printed for His Majesty's Stationery Office, by Darling \& Son, 1909. http://archive.org/ details/b21365398.

Staff Surgeon Wilm of the Imperial German Navy. "A Report on the Epidemic of Bubonic Plague at Hongkong in the Year 1896." Translated for the Government of Hongkong by Maurice Eden Paul, M.D. The Indian Medical Gazette 32, no. 5 (1897): 167-71.

---. "A Report on the Epidemic of Bubonic Plague at Hongkong in the Year 1896." The Indian Medical Gazette 32, no. 6 (June 1897): 207-9.

Thompson, J. Ashburton (John Ashburton), New South Wales. Department of Public Health, Guy's Hospital Medical School former owner, and King's College London. Report on the Outbreak 
of the Plague at Sydney, 1900 [Electronic Resource]. Sydney: W.A. Gullick, government printer, 1900. http://archive.org/details/ b21298968.

Wemple. "Report of a Case of Bubonic Plague." California State Journal of Medicine 2, no. 1 (1902): 40-42.

$\mathrm{Wu}$, Lien Teh. "First Report of the North Manchurian Plague Prevention Service." Journal of Hygiene 13, no. 3 (1913): 237-90 


\section{Endnotes}

1. Lorraine Daston, "The Sciences of the Archive," Osiris 27, no. 1 (January 1, 2012): 156-87, https://doi.org/10.1086/667826.

2. Anne Hardy and M. Eileen Magnello, "Statistical Methods in Epidemiology: Karl Pearson, Ronald Ross, Major Greenwood and Austin Bradford Hill, 1900-1945," Sozial- Und Präventivmedizin 47, no. 2 (March 1, 2002): 80-89, https://doi.org/ 10.1007/BF01318387.

3. Volker Hess and J. Andrew Mendelsohn, "Case and Series: Medical Knowledge and Paper Technology, 1600-1900," History of Science 48, no. 161 (2010): 287-314.

4. Many digital approaches to the history of diseases have been developed in recent years but the overwhelming amount of studies has focused on data sources that already exist in formalized and quantifiable form, such as mortality and morbidity statistics. See "Project Tycho," University of Pittsburgh, 2018, www.tycho.pitt.edu/ or K. Hempel and D. J. D. Earn, "A Century of Transitions in New York City's Measles Dynamics," Journal of The Royal Society Interface 12, no. 106 (May 6, 2015): 20150024, https://doi.org/10.1098/rsif.2015.0024.

5. Lukas Engelmann, "The Burial Pit as Bio-Historical Archive," in Histories of Post-Mortem Contagion, eds. Christos Lynteris and Nicholas Evans (Palgrave Macmillan, 2018), 189-211, https://doi.org/10.1007/978-3-319-62929-2 8.

6. Myron J. Echenberg, Plague Ports: The Global Urban Impact of Bubonic Plague, 1894-1901 (New York: New York University Press, 2007); Christos Lynteris, Ethnographic Plague: Configuring Disease on the Chinese-Russian Frontier (Palgrave Macmillan, 2016).

7. Alfredo Morabia, "On the Origin of Hill's Causal Criteria," Epidemiology 2, no. 5 (1991): 367-69; Alfredo Morabia, "Epidemiology: An Epistemological Perspective," in A History of Epidemiologic Methods and Concepts, ed. Alfredo Morabia (Boston: Birkhauser Verlag, 2004): 1-126 ; Alfredo Morabia, Enigmas of Health and Disease: How Epidemiology Helps Unravel Scientific Mysteries (New York; Columbia University Press, 2014).

8. "ENA," accessed 07/03/2018, http://www.epistemicnetwork.org. See also chapter 5 in this book by DiMeo and Ruis.

9. This point has been already raised by Crookshank in 1922: F. G. Crookshank, "First Principles of Epidemiology", in Influenza: Essays by Several Authors, ed. F. G. Crookshank (London: William Heinemann, 1922), 11-30.

10. Morabia, "Epidemiology: An Epistemological Perspective."

11. J. Andrew Mendelsohn, "From Eradication to Equilibrium. How Epidemics Became Complex after World War I.," in Greater Than the Parts: Holism in Biomedicine, 1920-1950, ed. Christopher Lawrence and George Weisz (Oxford University Press, 1998), 303-34. 
12. On the persistent lack of theory in the history of epidemiology: Nancy Krieger, "Got Theory? On the 21st Century Rise of Explicit Use of Epidemiologic Theories of Disease Distribution: A Review and Ecosocial Analysis," Current Epidemiology Reports 1, no. 1 (March 1, 2014): 45-56, https://doi.org/10.1007/s40471-013-0001-1; Nancy Krieger, Epidemiology and the People's Health: Theory and Context (Oxford University Press, 2011).

13. John M. Eyler, Victorian Social Medicine: The Ideas and Methods of William Farr (Cambridge: Cambridge University Press, 1979),

https://repository.library.georgetown.edu/handle/10822/782369; Kari S. McLeod, "Our Sense of Snow: The Myth of John Snow in Medical Geography, Social Science E Medicine 50, no. 7 (2000): 923-935; John M. Eyler, "The Changing Assessments of John Snow's and William Farr's Cholera Studies," Sozial- Und Präventivmedizin 46, no. 4 (July 1, 2001): 225-32, https://doi.org/10.1007/BF01593177; John M. Eyler, "The Strange Case of the Broad Street Pump: John Snow and the Mystery of Cholera," Journal of the History of Medicine and Allied Sciences; Oxford 63, no. 4 (October 2008): 525-26, http://dx.doi.org/10.1093/jhmas/jrn040; Tom Koch and Kenneth Denike, "Crediting His Critics' Concerns: Remaking John Snow's Map of Broad Street Cholera, 1854," Social Science \& Medicine 69 (2009): 1246-51; Tom Koch and Ken Denike, "Essential, Illustrative, or ... Just Propaganda? Rethinking John Snow's Broad Street Map," Cartographica: The International Journal for Geographic Information and Geovisualization 45, no. 1 (March 2010): 19-31, https://doi.org/ 10.3138/carto.45.1.19.

14. Jean-Paul Gaudilliére and Ilana Löwy, Heredity and Infection: The History of Disease Transmission (New York: Routledge, 2012).

15. John M. Eyler, "William Farr on the Cholera: The Sanitarian's Disease Theory and the Statistician's Method," Journal of the History of Medicine and Allied Sciences; Oxford 28, no. 2 (April 1, 1973): 79-100.

16. Erwin H. Ackerknecht, "Anticontagionism between 1821 and 1867," Bulletin of the History of Medicine 22 (1948): 562-93.

17. Anne Hardy and M. Eileen Magnello, "Statistical Methods in Epidemiology: Karl Pearson, Ronald Ross, Major Greenwood and Austin Bradford Hill, 1900-1945," Sozial- Und Präventivmedizin 47, no. 2 (March 1, 2002): 82, https://doi.org/10.1007/ BF01318387.

18. Anne Hardy, The Epidemic Streets: Infectious Disease and the Rise of Preventive Medicine, 1856-1900 (Wotton-under-Edge: Clarendon Press, 1993); Graham Mooney, Intrusive Interventions: Public Health, Domestic Space, and Infectious Disease Surveillance in England, 1840-1914 (Woodbridge: Boydell \& Brewer, 2015).

19. F. A. Barrett, "August Hirsch: As Critic of, and Contributor to, Geographical Medicine and Medical Geography," Medical History. Supplement, no. 20 (2000): 98-117.

20. Volker Hess and Andrew Mendelsohn, "Sauvages' Paperwork: How Disease Classification Arose from Scholarly Note-Taking," Early Science and Medicine 19, no. 5 (2014): 471-503. 
21. August Hirsch, Handbook of Geographical and Historical Pathology (London: New Sydenham Society, 1883); on the role of aleatoric series and the comparability of the spatial arguments attributed to disease in the individual and the social body, see Michel Foucault, The Birth of the Clinic: An Archaeology of Medical Perception (New York: Pantheon Books, 1973).

22. Echenberg, Plague Ports.

23. D. J. Bibel and T. H. Chen, "Diagnosis of Plaque: An Analysis of the Yersin-Kitasato Controversy," Bacteriological Reviews 40, no. 3 (September 1976): 633-51.

24. On the incommensurability of bacteriology and epidemiology at the time, see J. Andrew Mendelsohn, "Like All That Lives': Biology, Medicine and Bacteria in the Age of Pasteur and Koch," History and Philosophy of the Life Sciences 24, no. 1 (2002): 3-36.

25. J. Andrew Mendelsohn, "Like All That Lives."; Andrew Cunningham, "Transforming Plague: The Laboratory and the Identity of Infectious Disease," in The Laboratory Revolution in Medicine, ed. Andrew Cunningham and Perry Williams (Cambridge: Cambridge University Press, 1992), 209-44.

26. An argument that was made in particularly strong form by the Pasteurian Calmette: Albert Calmette, The Plague at Oporto (The North American Review, 1900).

27. Guenter B. Risse, Plague, Fear, and Politics in San Francisco's Chinatown (Baltimore: Johns Hopkins University Press, 2012); Nayan Shah, Contagious Divides: Epidemics and Race in San Francisco's Chinatown (Berkeley: University of California Press, 2001); Lynteris, Ethnographic Plague.

28. William John Ritchie Simpson, A Treatise on Plague; Dealing with the Historical, Epidemiological, Clinical, Therapeutic and Preventive Aspects of the Disease (Cambridge, UK: Cambridge University Press, 1905), http://archive.org/ details/treatiseonplague00simp; Christos Lynteris, "A Suitable Soil: Visualizing Plague's Environment during the Third Pandemic" (presentation, The Plague and the City, Cambridge, December 5, 2014); David S. Barnes, "Cargo, 'Infection,' and the Logic of Quarantine in the Nineteenth Century," Bulletin of the History of Medicine 88, no. 1 (2014): 75-101, https://doi.org/10.1353/bhm.2014.0018.

29. J. Danysz, "Some Reflections Regarding the Free Use of Bacteriological Cultures for the Destruction of Rats and Mice," British Medical Journal 1, no. 2508 (1909): 209; Mendelsohn, "Like All That Lives."

30. This, of course, is problematic; as, for example, many contributions from the Institut Pasteur were written in French, almost all Latin American outbreaks were covered either in Spanish or Portuguese and many Chinese and Russian observations only exist in their respective languages. This bias, which follows the macro-political lines of the British and the American Empire, structures this first pilot study and needs to be taken accordingly into account.

31. John Swales, Genre Analysis: English in Academic and Research Settings (Cambridge: Cambridge University Press, 1990); V. K. Bhatia, Analysing Genre: Language Use in Professional Settings (New York: Routledge, 2014). 
32. John Flowerdew and Alina Wan, "The Linguistic and the Contextual in Applied Genre Analysis: The Case of the Company Audit Report," English for Specific Purposes 29, no. 2 (April 1, 2010): 78-93, https://doi.org/10.1016/j.esp.2009.07.001.

33. Lowson, "Medical Report on the Epidemic of Bubonic Plague in Hong Kong," Chinese Medical Missionary Journal 9, no. 3) (1895): 141-47.

34. Ernest Edward Hill, "Report on the Plague in Natal, 1902-3" (London: Cassell, 1904), http://archive.org/details/b2135392x.

35. C. R. Eskey, "Epidemiological Study of Plague in Peru," Public Health Reports 47 (1932): 2191-2207. 